УДК 323

Научная статья

DOI 10.18101/2306-630X-2020-1-54-60

\title{
«АДСКИЙ ЧОСОН» \\ КАК ФАКТОР ПОЛИТИЧЕСКОЙ АКТИВНОСТИ В ЮЖНОЙ КОРЕЕ
}

\author{
(C) Бритова Виктория Римовна \\ ассистент, \\ Бурятский государственный университет имени Доржи Банзарова \\ Россия, 670000, г. Улан-Удэ, ул. Смолина, 24a \\ mengly@mail.ru
}

\begin{abstract}
Аннотация. В данной статье исследуется феномен «адский Чосон» в Южной Корее на примере выступлений против президента Пак Кын Хе в 2017 г. Мы рассматриваем данный феномен как один из факторов яркого всплеска политической активности в Корее, в итоге оказавший значительное влияние на объявление импичмента президента Пак Кын Хе. Трудности в поиске работы, отказ от личной жизни, отсутствие возможности самообеспечения оказывают негативное влияние на восприятие собственной страны молодыми корейцами. В поисках образа Кореи в глазах молодых корейцев в статье разобрана картина «адского Чосона». В статье сделан вывод о том, что неустроенность молодежи в социально-экономическом плане и отсутствие государственной поддержки в конечном итоге приводят к отказу от самореализации.

Ключевые слова: Южная Корея; политика; общество; власть; экономика; молодежь Южной Кореи; политические протесты; президент Пак Кын Хе.
\end{abstract}

\section{Для цитирования}

Бритова В. Р. «Адский Чосон» как фактор политической активности в Южной Корее // Евразийство и мир. 2020. № 1. С. 54-60.

Молодежь в современном мире испытывает множество сложностей на пути к самореализации и достижению социального и экономического статуса. Трудоустройство, обеспечение жильем, создание семьи становятся наиболее важными потребностями в жизни молодого человека. Проблемы, с которыми он сталкивается в ходе удовлетворения своих потребностей, оказывают влияние на его мироощущение и мировосприятие. Государство в данном случае выступает как гарант стабильности и уверенности человека в своем будущем, поэтому если гарантия государственной поддержки оказывается под вопросом, то молодежь, как движущая сила общества, начинает входить в оппозицию к государству. Противопоставляя себя государству, молодые люди выражают свое неудовольствие в различных протестных акциях, будь то митинги, организации акций, интернет-деятельность и т. д. Правительство страны находится под внимательным наблюдением множества лиц, каждое его действие вызывает реакцию и отклик среди населения, а молодежь, являясь одной из нестабильных социальных групп, пропускает меры правительства через сито своих ожиданий и воззрений.

Подобные тенденции протестных движений отмечаются во множестве стран, азиатские страны не являются исключением. Южная Корея как один из носителей 
традиций конфуцианской культуры, в которой укоренено уважительное отношение к старшим, будь это родитель, начальник или президент, показывает из года в год, как устои конфуцианского почтения постепенно уступают западным, демократически настроенным ценностям культуры. В данном случае это касается фигуры президента, а именно дела об импичменте южнокорейского президента Пак Кын Хе (2013-2017 гг.). Рассмотрим, какие факторы повлияли на выступления молодежи Южной Кореи против президента Пак Кын Хе. Но прежде всего необходимо напомнить историческую канву данного события.

В Южной Корее, как и в ряде стран, происходят различные политические пертурбации, связанные со снижением доверия населения к власти. Одним из самых мощных политических кризисов Кореи можно назвать скандал сунщиль гейт (최순 실 게이트) 2016 г., утечка государственных документов подруге президента Пак Кын Хе (2013-2017) - Чхве Сун Щиль - с одобрения самого президента. Когда СМИ Кореи обнародовали информацию об этом, разразился страшный скандал, в который оказались вовлечены почти все уровни власти и бизнеса. Отмечалось участие Чхве Сун Щиль в коррупционной схеме, в которую были вовлечены главы крупнейших конгломератов Кореи, таких как Самсунг, Хёндэ, группы CK (SK Group) и Лотте (Lotte Group), когда на счета фондов, подотчетных Чхве (фонды Mir и K-Sport), поступали средства от данных компаний в обмен на уступки государства бизнесу [1]. Несмотря на извинения и прочие попытки президента Пак Кын Хе сохранить политическое положение, в декабре 2016 г. члены Национального Собрания - парламента Республики Кореи - по итогам тайного голосования объявили президенту импичмент, а в марте 2017 г. Конституционный Суд Кореи утвердил это решение. После ухода с поста президента в апреле 2017 г. против Пак Кын Хе было заведено уголовное дело, и в 2018 г. он и его подруга Чхве Сун Щиль были осуждены на 25 и 20 лет соответственно ${ }^{1}$.

Данный скандал отличался широким общественным резонансом, выразившимся в манифестациях и митингах за уход президента с поста. Массовые демонстрации шли в Корее с того момента, как в конце октября 2016 г. стало известно об участии Чхве Сун Щиль в государственных делах, вплоть до объявления импичмента Пак Кын Хе в декабре 2016 г. Демонстрации отличались большим количеством участников, по оценкам организаторов в марше протеста 26 ноября 2016 г. в Сеуле принимало участие около 1,3 млн человек [2], а уже 3 декабря 2016 г. в митингах против президента по всей Корее участвовали рекордные 2 млн 150 тыс. человек [3]. Известный кореевед А. Ланьков говорит о том, что гражданское общество Кореи показало свою силу и бесстрашие, не побоявшись бросить вызов президенту [4]. Во многом именно столь масштабное недовольство населения повлияло на ускорение процедуры импичмента.

Мы думаем, что не только сунщильгейт вызвал столь обширный общественный резонанс, но и ряд других проблем, существующих в отношениях общества с государством, мог спровоцировать подобные события. Скандал с утечкой государственных документов и коррупцией мог стать конечной точкой недовольства общества прези-

\footnotetext{
${ }^{1}$ Бывшему президенту Южной Кореи ужесточили приговор [Электронный ресурс] // Новая газета. URL: https://novayagazeta.ru/news/2018/08/24/144459-byvshemu-prezidentu-yuzhnoykorei-uzhestochili-prigovor (дата обращения: 08.04.2020).
} 
дентом. Дело в том, что рейтинг доверия к президенту еще до начала скандала был довольно низок и составлял не более 30-35\%, а по мере развития клубка событий в октябре-ноябре 2016 г. упал до рекордных 4\% ${ }^{1}$. Кореевед К. Асмолов говорит, что снижение доверия к президенту наблюдалось еще задолго до событий 2016 г., это было связано с введением непопулярных мер в сфере трудового законодательства (ограничение системы пожизненного найма в пользу временных трудовых договоров), реформы образования (сокращение числа университетов) и антикоррупционного закона, устанавливающего нижний предел стоимости званых обедов и подарков, в конечном итоге недовольство действиями президента стало выражаться отчетливей [5]. Поэтому люди, чьи интересы были затронуты действиями президента, активно выступали за уход Пак Кын Хе с поста, невзирая на тот факт, что его отец легендарный президент Пак Чон Хи (1962-1979), создатель корейского экономического чуда в 70-х гг. XX в. Если посмотреть показатели поддержки по возрастным группам, то получается, что 99\% граждан в возрасте 19-29 лет и 98\% граждан в возрасте 30 лет не одобряли политику президента, в то время как только 9\% граждан в возрасте 60 лет ее поддерживали'․ Таким образом очевидно, что в большинстве случаев действиями президента Пак Кын Хе оставались недовольны молодежь и люди среднего возраста, что приводит к идее о необходимости более подробного анализа существующих проблем населения Кореи. Ведь если бы президент имел популярность среди данных групп населения, то вряд ли бы скандал вызвал бы столь обширный общественный резонанс.

По нашему мнению, своеобразным воплощением претензий населения к правительству является понятие хэлчосон (헬조선, адский Чосон), которое также имеет синонимы в виде чжиокпульпандо (지옥불반도, адский полуостров) и манханмингук (망한민국, страна упадка). Термин хэлчосон подразумевает собой совокупность всех проблем современного корейского общества, с которыми так или иначе сталкиваются жители южной части Корейского полуострова. Особенно ярко отражено его использование среди молодежи, выражающей в данном термине неприязнь и нелюбовь к родине, так как число трудностей, с которыми сталкивается молодежь, оказывается для них непосильным и непреодолимым препятствием на пути к жизненному успеху. Впервые термин хэлчосон появился на корейском интернет-форуме Dcinside в 2011 г., со временем интерес к этому явлению возрос и в 2014-2015 гг. достиг своего пика, в 2015 г. слово хэлчосон являлось вторым по частоте употребления термином в СМИ Кореи, уступая лишь кымсучжо (금수저, родиться с серебряной ложкой во рту) ${ }^{3}$. Также начал работу одноименный сайт (hellkorea.com), ставивший своей задачей объединение недовольных жизнью в Корее, где в основном поднимались темы несправедливости, чрезмерного давления при поступлении в университет,

\footnotetext{
${ }^{1}$ Итоги деятельности Пак Кын Хе на посту президента Республики Корея [Электронный pecypc] // Досье. TACС. [Электронный ресурс]. URL: https://tass.ru/info/4084225. (дата обращения: 08.04.2020).

${ }^{2}$ Hundreds of thousands gather in South Korea to protest President Park Geun Нуе [Электронный ресурс] // Telegraph. 2016. 26 нояб. URL: https://www.telegraph.co.uk/.../hundredsthousands-gather-south-korea- protest-against-president (дата обращения: 08.04.2020).

3 [비하인드뉴스], '헬조선' 신조어대신 '노오력'을? // JTBC News. 2016.16 авг. URL: https://www.youtube.com/watch?v=yvNeYL5PLK0 (дата обращения: 08.04.2020).
} 
трудности с поиском работы, созданием семьи, обеспечения жизни. В противовес термину хэлчосон также появилось понятие тхальчосон (탈조선, побег из Чосона), то есть вынужденная эмиграция в поисках лучшей доли.

Корейцы объясняют термин хэлчосон как 지옥과 같은 한국 - Корея, подобная аду. В данном случае современная Корея уподобляется государству Чосон (1392-1897) к исходу своего существования в конце XIX в. на пороге начала японского протектората (1910-1945) в Корее. Один из пользователей сети Интернет в Корее создал карту адского Чосона, на котором были описаны все этапы жизни современного корейца. Эта карта была создана на основе известной компьютерной игры World of Warcraft и получила широкую известность среди корейской молодежи. Мы решили рассмотреть более подробно ее содержание, чтобы понять, какие проблемы и препоны волнуют корейцев больше всего. Сами корейцы при описании жизни в адском Чосоне используют выражение 아무리 노력해도 바뀌는 것 없다, дословно это значит, как бы ты ни старался, ничего не меняется, то есть выше головы все равно не прыгнешь, если ты, к примеру, не родился в семье владельцев промышленного конгломерата - то есть не являешься кымсучжо, человеком, родившимся с серебряной ложкой во рту.

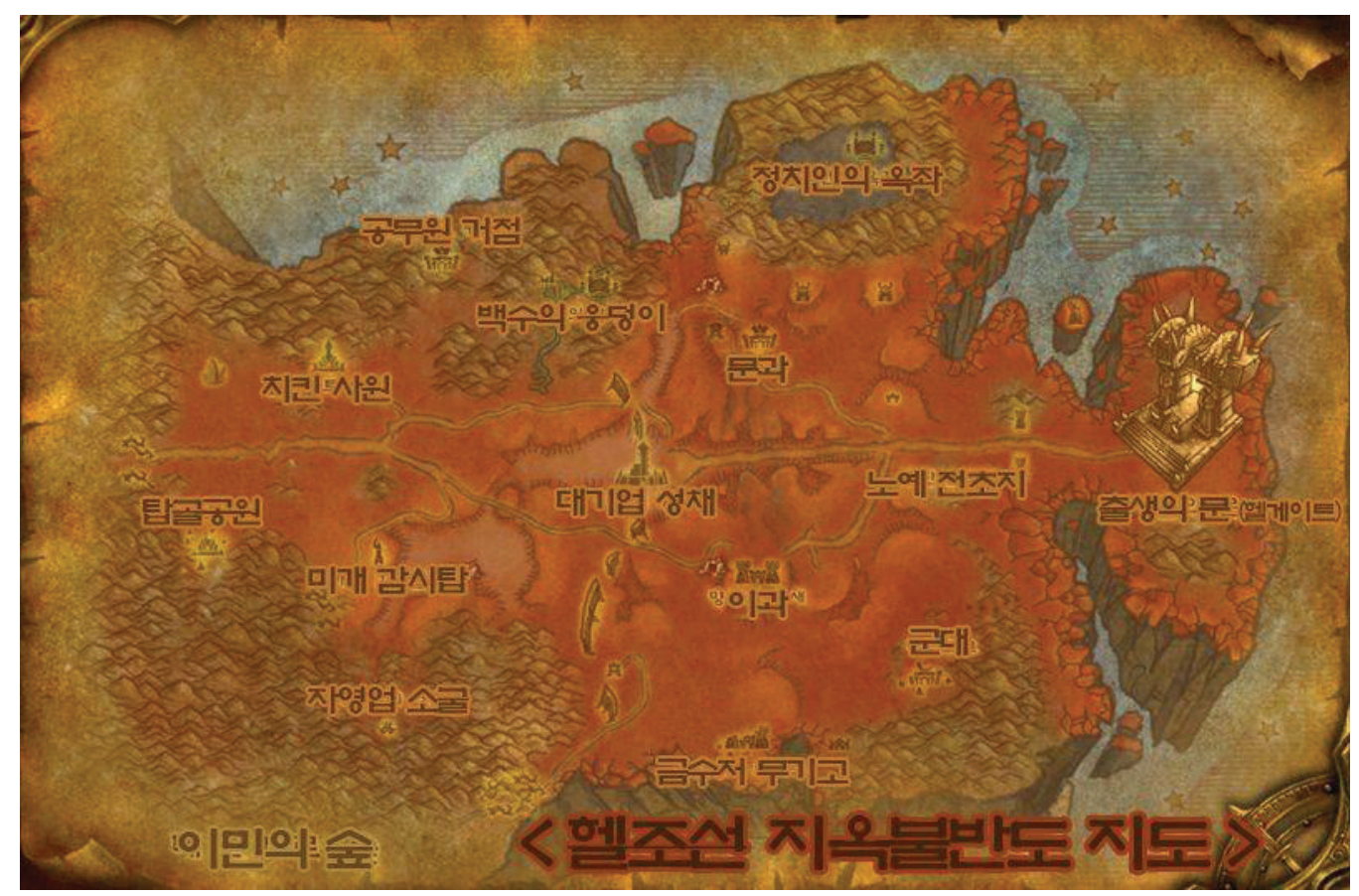

Рис. 1

Все начинается с рождения в адском Чосоне - 출생의 문 (헬게이트) врата в Ад. После него начинается этап обучения, основанный на зубрежке - 주입식 교 육, который иначе называется этапом подготовки к рабству (예비 노예로 노예 전 초지에서 살아가다, жить на переднем крае рабства в качестве будущего раба). Далее наступает деление в образовании члена адского Чосона: 이과 - естественные 
науки, 문과 - гуманитарные. В промежутке между зубрежкой и поступлением в университет может появиться армия 군 대. Есть люди, способные избежать всех этих трудностей, это либо те, кто родился в семье богачей 금수저 무기고 и его происхождение позволяет ему вести комфортную жизнь, либо это люди, пользующиеся комфортом благодаря трону политика 정치 인의 옥좌, то есть люди, имеющие родство с политиками. После получения образования у человека появляется несколько перспектив, первая и самая главная - это трудоустройство в так называемую крепость крупного предприятия 대기업 성채, если этого не происходит вследствие высокой конкуренции кандидатов или высоких требований работодателей, то человек может оказаться в яме безработииы 백수의 웅동이, причем если человек получал образование по гуманитарному профилю (문 과), тем выше вероятность, что он попадет именно туда. Либо он может попытаться сдать экзамены на государственную должность и получить положение госслужащего 공무원 거점. Также он может начать заниматься собственным бизнесом, создать так называемое логово частного предпринимательства 자영 업 소굴, причем наиболее характерным примером это будет храм жареной курищь 치킨 사원, так как торговля жареной курицей является наиболее распространенной формой предпринимательства, своего рода его символом. Схематично эту борьбу за место под солнцем описывает фразеологизм 각자도생 каждый стремится выжить. И, наконец, жизнь в адском Чосоне приводит к тому, что все люди оказываются в парке Тапколь 탑골공원, то есть стареют и становятся подобны старикам, играющим в традиционные корейские шахматы чанги (장기) либо в игру падук (바둑) в парке Тапколь (г. Сеул).

Из адского Чосона можно выбраться, если человек вступит в лес эмиграции 이민의 솦, то есть просто переедет в другую страну и тем самым осуществит так называемый 탈조선 побег из Чосона. Согласно опросам на сайте трудоустройства (saramin.co.kr), около 80\% респондентов хотели бы эмигрировать из Кореи, если бы имели возможность. Отмечается, что больше всего хотели бы переехать люди в возрасте 30 лет $(82.1 \%)$, а также 20 -летние $(80 \%)$ и 40 -летние $(72.4 \%)^{1}$.

Необходимо отметить особое место на карте адского Чосона в промежутке между работой и старостью - 미 개 감시탑 (дикая сторожевая башня) - пространcтво свободы, то есть отказ от всего. Это связано с тенденцией молодого поколения отказываться от брака, семьи, жилья и т. д., так как возможностей для обеспечения такой жизни они не наблюдают. Это отражено в выражениях 삼포세 대 отказ от 3 вещей - любви, семьи и детей, 오포세 대 отказ от 5 вещей - любви, семьи, детей, личных взаимоотношений и жилья, наконец, N포세 ᄃㅐ, то есть отказ от всего.

Также стоит отметить противопоставление таких понятий, как 금수저 кымсучжо серебряная ложка и 흙수저 хыльксучжо ложка из грязи, в первом случае это представители высшего класса Кореи, которые избегают жизни в адском Чосоне благодаря своему происхождению (кымсучжо), а основная масса населения Кореи представлена хыльксучжо, людьми, не имеющими особых возможностей и вынужденными выживать, а не жить в Корее. На видеохостинге Youtube размещен ролик программы Saturday Night Life Korea, описывающий в юмористическом ключе жизнь в адском Чосоне, где проводятся параллели между старым Чосоном,

1 본지 — 사람인설문] 한국인 $80 \%$ '이민가고싶다' ...왜?, 해럴드경제. 2016. 18 янв. URL: http://news.heraldcorp.com/view.php?ud=20160118000058 (дата обращения: 08.10.2020). 
где существовала относительно развитая система социальных мер, и современной Кореей, где эти меры отсутствуют ${ }^{1}$. Например, в записях правления короля Сечжона (세종실록) указывается, что женщина из низшего сословия ноби (лично зависимые крестьяне) после рождения ребенка имеет право отдыхать сто дней, а ее супруг тридцать ${ }^{2}$. Также в истинных записях династии Чосон (조선왕조실록) говорится, что каждый старик, достигнув 100-летнего рубежа, может получить от государства рис, водку и мясо, так король Сечжон в ответ на предложение сократить некоему Киму в возрасте 100 лет объем выдаваемого риса, говорит, чтобы довольствие сохраняли в прежнем объеме ${ }^{3}$. Узнав о существовании подобных социальных мер, герой ролика говорит, что времена Чосон оказываются лучше современных (조선 시대가 지금보다 낫다), так как в настоящей Корее таких условий нет.

Интересно отметить, что главной причиной подобной невыносимой жизни в Корее корейцы называют недоверие к власти (46\%). Помимо этого корейцев беспокоит неуверенность в будущем (24\%) и неустойчивая рабочая обстановка $(13 \%)^{4}$. Таким образом, поскольку главным препятствием к счастливой жизни, по мнению большинства населения Кореи, является государство, вполне естественно, что именно против правительства Кореи будет направлена ненависть общества. Эта ненависть находит выражение в демонстрациях и митингах, в которых участвуют практически все заинтересованные в своих правах люди. И как показывает история с импичментом Пак Кын Хе, общество не прощает ошибок, непопулярных мер и в конечном итоге сумеет бросить вызов даже президенту, если условия жизни окажутся невыносимыми и большей части населения будет нечего терять.

Мы рассмотрели явление адского Чосона как фон политического скандала сунщилльгейт и импичмента Пак Кын Хе. Мы думаем, что не только жизнь адского Чосона повлияла на столь резкую реакцию общества на утечку данных и коррупцию приближенных к президенту, но и ряд других причин, связанных с деятельностью президента и общим впечатлением от его стиля управления. Тем не менее восприятие собственного государства как адского места, в котором нет условий для нормального проживания, если по происхождению ты не с серебряной ложкой кымсучжо 금수 저, a с земляной хыксучжо 흙수저, а государство не спешит это изменить и даже поощряет, может стать отправной точкой для бунта против государства.

Литература

1. Кирьянов О. Скандал в Южной Корее: Пак Кын Хе может лишиться кресла президента [Электронный ресурс] // Российская газета. 2018. 20 июля. URL: https://rg.ru/2016/10/28/ skandal-v-iuzhnoj-koree-pak-kyn-he-mozhet-lishitsia-kresla-prezidenta.html (дата обращения:

\footnotetext{
1 SNLKorea [Электронный ресурc]. URL: https://www.youtube.com/watch?v=WOunX7X_ qJM (дата обращения: 08.10.2020).

2 세종실록, 32권, 8년 4월 17일, Записи правления короля Сечжона, 32 том, 8 год, 4 месяц, 17 день правления короля Сечжона.

3 조선왕조실록, 74 권, 세종 18년 7월 27일, Истинные записи династии Чосон, 74 том, 27 день, 7 месяц, 18 год правления короля Сечжона [Электронный ресурc]. URL: http://sillok. history.go.kr/id/kda_11807027_002 (дата обращения: 08.10.2020).

4 지옥의 한국, 헬조선' 현상 JTBC [Электронный pecypc]. URL: http://news.jtbc.joins.com/ article/article.aspx?news_id=NB11036167 (дата обращения: 08.10.2020).
} 
20.04.2020).

2. Плясункова Е. В Южной Корее около 1,6 млн человек вышли протестовать против президента [Электронный ресурс] // РИА новости. 2016. 26 нояб. URL: https://ria. ru/20161126/1482239871.html (дата обращения: 20.04.2020).

3. Кирьянов О. В Корее прошли рекордные по масштабу демонстрации [Электронный ресурс] // Российская газета. 2016. 3 дек. URL: https://rg.ru/2016/12/03/v-koree-proshlirekordnye-po-masshtabu-demonstracii-protiv-pak-kyn-he.html (дата обращения: 20.04.2020).

4. Ланьков А. Самое сильное гражданское общество Восточной Азии [Электронный pecypc] // Carnegie.ru.URL: https://meduza.io/feature/2016/11/24/samoe-silnoe-grazhdanskoeobschestvo-vostochnoy-azii (дата обращения: 20.04.2020).

5. Асмолов К. Импичмент Пак Кын Хе: причины и последствия [Электронный ресурс] // РСМД. 2016. 16 дек. URL: https://russiancouncil.ru/analytics-and-comments/analytics/ impichment-pak-kyn-khe-prichiny-i-posledstviya (дата обращения: 20.04.2020).

"INFERNAL JOSEON" AS A FACTOR OF POLITICAL ACTIVITY IN SOUTH KOREA

Viktoria R. Britova

Assistant,

Dorzhi Banzarov Buryat State University

24a Smolina St., Ulan-Ude 670000, Russia

mengly@mail.ru

Abstract. The article discusses the phenomenon of the "Infernal Joseon" in South Korea on the example of the protests against President Park Geun-hye in 2017. We consider this phenomenon as one of the factors of a surge in the political activity of Korea, which eventually had a strong effect on the impeachment of President Park Geun-hye. Difficulties in finding a job, abandonment of private life, and lack of self-sufficiency have a negative impact on the perception of Korea by youth. We have analyzed the image of Korea in the eyes of young Koreans through the concept of "Infernal Joseon". It is concluded that the social and economic exclusion of young people and the lack of state support ultimately leads to the problems in their self-actualization.

Keywords: South Korea; policy; society; government; economy; South Korean youth; political protests; President Park Geun-hye.

Статья поступила в редакцию 12.04.20; одобрена после редактирования 30.04.20; принята к публикации 30.10 .20 . 